\title{
Erratum to: Neonatal Pain- Suffering, Pain, and Risk of Brain Damage in the Fetus and Newborn, Second Edition
}

\section{Giuseppe Buonocore and Carlo Valerio Bellieni}

\section{Erratum to:}

Chapters 20, 21 and 22 and Appendix in: Giuseppe Buonocore and Carlo Valerio Bellieni Neonatal Pain, DOI 10.1007/978-3-319-53232-5

Owing to an unfortunate oversight the contribution by Karel Allegaert and John N. van den Anker was initially published as an Appendix to the book and incorrect authorship had been provided. It has now been changed into a regular chapter and author names have been corrected. The Appendix has been integrated as chapter 20, "Drawbacks of Analgesics in Neonatal Age: How to Ensure Safe and Effective Use in Newborns"

As a consequence the chapter numbers and the page numbers for the following chapters have changed compared to the originally published versions as follows:

Chapter 20: Disclosure of Pathology to the Newborn's Family by P. Arosio has become chapter 21

Chapter 21 Pain and Grief in the Experience of Parents of Children with a Congenital Malformation by Luigi Memo and Emanuele Basile has become chapter 22

Chapter 22 Invest in Prenatal Life: A High-Yield Stock by M. Enrichi has become chapter 23

In addition, the Preface and the Introduction have been included in the Table of Contents.

\footnotetext{
The updated online versions of Chapters 20,21, 22, and 23 can be found at:

DOI 10.1007/978-3-319-53232-5_23

DOI 10.1007/978-3-319-53232-5_20

DOI 10.1007/978-3-319-53232-5_21

DOI 10.1007/978-3-319-53232-5_22
} 